\title{
Chemoprophylaxis with DDS, mainly in children: A short trial
}

\author{
RODOLPHE A. BREGHET, м.D., \\ Caluquembe, Angola.
}

The Eighth International Congress of Leprology at Rio de Janeiro in I 963, stressed the importance of chemoprophylactic trials, and we report our experiences in an African 'milieu' facing the difficulties of effective protection of children from the infection.

We first tried chemoprophylaxis on a limited scale in two 'homes for healthy children of leprosy patients'. We do not report results in detail in this paper, but can say that the results were encouraging, except for one person.

In I 960 we began a larger scheme at our main leprosarium (Jamba). As no unfavourable results were noted, we progressively extended the scheme to 3 other institutions. So far the experiment covers only a few years and we hope to report fuller results after several more years.

In the present trial there were 97 adult leprosy patients who had 864 children as contacts: ('child' means I 5 years of age or less). There was a loss of ${ }_{1} 6$ I children from the chemoprophylaxis trial, mainly because their parents left the institution. Only 9 children stayed in the institutions but they are not being given drug prophylaxis.

In spite of this, there are at present 703 children in our 4 leprosy institutions who are taking chemoprophylaxis, of whom 6 I 5 attend regularly and 88 irregularly. The total patient population of the institutions is about 1400 .

The duration of the prophylaxis varies according to time of initiation of the drug prophylaxis. Thus in Jamba 363 persons have had $3 \frac{1}{4}$ years of chemoprophylaxis, in Catala I4I have had 3 years, in Caluquembe i i 5 have had $2 \frac{1}{4}$ years, and in Cavangu 245 children have had 2 years.

Age of onset of dosage has been 5 months to I 2 months for infants, advantage being taken of the prophylactic effect of DDS in maternal milk and that giving of tablets to small children could be avoided. About 2 to 5 years $50 \mathrm{mgm}$. orally twice a week was given and from June I 964 reduced to once a week, the dosage being: $50 \mathrm{mgm}$. once a week for children up to 3 years of age.

I oo mgm. , , , , , ,, the rest of the children.

200 mgm. ,, ,, ,, ,, adults.

Medical observations were simple and included recording of weight, haemoglobin level, and the lepromin reaction.

\section{RESULTS}

Not a single leprosy manifestation has appeared in the contacts up to end of November I 964 . There was only one doubtful case who might already have been a leprosy infection but who disappeared from observation and later was reported to have died at home.

Toxic effects have been minimal.

\section{B EN E FICIA L EFFEGTS}

(I) incidence of other illnesses became less; (2) better general health; (3) lack of fear of leprosy and lack of psychological dread of separation from parents because the children could live a normal family life.

Attitude of Parents was good, with great satisfaction at this prophylaxis. They easily understood the principle of chemoprophylaxis. Co-operation has been very good.

\section{I S G US I O N}

We did not have a control group because of technical and psychological difficulties, and propose to use the experiences of former years as control. Thus in the years from 1947 to 1964 
at least 360 children were treated for leprosy, and I 78 (or $49.2 \%$ ) had parents or relatives who suffered from leprosy. Of apparently healthy children there were in the past an appreciable proportion who developed leprosy later. This has ceased under the prophylactic regime.

S U M M A R Y

The dramatic disappearance of leprosy incidence in healthy children living in contact with leprosy patients, the absence of notable toxic effects, the additional benefits, together with the low price of DDS, makes chemoprophylaxis a simple and easy method of prevention of the more susceptible human group. The results encourages a wide use of this method.

\section{A CKNOWLEDGEMENTS}

Thanks to the 4 nurses directing the 4 institutions for their co-operation and help in preparation of much of the material of this report, namely Miss Alice Moreira, Miss Hanni Sigg, Miss Elsi Guildimann, and Miss Gandhi Marinova. 